\title{
MSMEs as Engine of Economic Growth in Nigeria: Challenges and Prospects of Scalability
}

\author{
Emmanuel Okokondem Okon ${ }^{1}$
}

\begin{abstract}
${ }^{1}$ Department of Economics, Kogi State University, Anyigba, Kogi State, Nigeria
Correspondence: Department of Economics, Kogi State University, Anyigba, Kogi State, Nigeria, E-mail: tonydom57@yahoo.com. Tel: +2348023275716
\end{abstract}

Received: January 13, 2018

Accepted: January 15, 2018

Online Published: January 19, 2018

\begin{abstract}
Growing or expanding the Micro, Small and Medium Enterprises (MSMEs) sector of the economy is one key strategy to achieve economic growth and development. Micro, Small and Medium Enterprises (MSMEs) scalability (growth or expansion) have become an area of concern for economic growth in developing economies. People use the term in reference to computer or other technological systems, but those in business also use the word to describe the adaptability of a company (Thibodeaux, 2015) in today's fast-paced business environment where the focus on customer satisfaction is at an all-time high. This article discusses the concept of scalability as it relates to business and non-scalable components of business process as well as the importance of being scalable. It also looked at some of the challenges and practices that prevent effective scalability of MSMEs in Nigeria and the way forward.
\end{abstract}

Keywords: MSMEs, challenges, scalability, economic growth, Nigeria

\section{Introduction}

Micro, Small and Medium Enterprises (MSMEs) account for a large proportion of the total employment growth in many countries. In such countries, MSMEs produce a significant share of their increases in Gross Domestic Product (GDP), while the contributions of larger enterprises tend to remain stable (ADB, 2002). For instance, in the OECD economies, MSMEs and micro enterprises account for over 95\% of firms, $60-70 \%$ of employment, 55\% of GDP and generate the lion's share of new employment. In the case of developing economies, the situation is not very different. For instance, in Morocco, 93\% of firms are MSMEs and account for 38\% of production, 33\% investment, $30 \%$ export and $46 \%$ employment. Similarly, in Bangladesh, enterprises of less than 100 employees account for 99\% of all firms and 58\% employment. Also, in Ecuador, 99\% of all private companies have less than 50 employees and account for $55 \%$ of employment (Etuk et al., 2014).

In the case of Nigeria, well-managed and healthy MSMEs constitute significant sources of employment opportunities and wealth creation. While the citizens benefit in terms of employment and income, Government also benefits by generating revenue in form of taxes. This can be a strong factor to social stability. It is noteworthy that not all MSMEs and microenterprises are in the formal sector; some of them occupy the unofficial labour market, which varies in size from an estimated $4-6 \%$ in developed countries to over $50 \%$ in developing nations. According to the International Finance Corporation (IFC, 2006), there is a positive relationship between a country's overall level of income and the number of MSMEs per 1,000 people. The World Bank's Doing Business reports indicate that a healthy MSME sector corresponds with a reduced level of informal or "black market" activities. Thus, managing MSME sector to reduce the number of informal business is essential in the Nigerian development project. MSMEs are regarded as the bedrock of industrialization. Because a number of them possess extensive knowledge of resources, as well as demand and supply trends, they constitute the chief supplier of input to larger firms. They also serve as the main customers to the larger firms; provide all sorts of products ranging from food, clothing, recreation, 
entertainment, healthcare, education, and so forth. They help in economic development through industrial disposal and production of primary and intermediate products. They can also supply the material needs of the larger enterprises. In addition, they provide specialized, and many times, personal services. In summary, MSMEs constitute important sources of local supply and service provision to larger corporations (Etuk et al., 2014).

Developing countries represent a huge, largely untapped market for large corporations. By working closely with MSMEs, large corporations can develop new customer base that may not be accessible to the traditional distribution networks of these corporations. MSMEs also represent important sources of innovation. They tend to occupy specialized market "niches" and follow competitive strategies that set them apart from other companies. This might include re-engineering products or services to meet market demands, exploring innovative distribution or sales techniques, or developing new and untapped markets. This often makes them good partners for large corporations.

In the financial sector, emerging economies represent a huge potential market for credit, particularly in sub-Saharan Africa, where according to the United Nations Capital Development Fund (UNCDF), only $4 \%$ of Africans have a bank account. Local financial institutions that have successfully served the MSMEs market in developed countries have found it highly profitable, according to United Nations Conference on Trade and Development (UNCTAD, 2001). Large international banking groups are beginning to tap into these markets. For instance, today Barclays Bank is present in 12 African countries, employs 41,000 people - one-third of its total workforce - and has 8 million customers. Africa accounts for $13 \%$ of the group's profits. Barclays has worked to integrate MSMEs into its operations. In their efforts to localize value creation, many large companies in the world increasingly rely on local companies as a crucial component of their value chain. Furthermore, MSMEs help in the development of local technology and mobilization and utilization of domestic savings. Thus, increases in MSME efficiency can also improve the competitiveness of larger firms that depend on MSME suppliers, and therefore improve the competitive position of a country's economy.

MSMEs tend to be more labour intensive than larger firms, and capital requirements for establishing them are low. This widens the chances of many individual to participate in them and by so doing contribute to industrial development. Moreover, the size and structure of MSMEs give them flexibility in management approaches which make them respond swiftly to changes and adapt to market needs much more quickly than their large enterprise counterparts in comparable industries. Thus in these days of increased emphasis on private-sector-driven economy, MSMEs act as engines of the much desired private-sector-led economic growth and diversification (Etuk et al., 2014).

Growing or expanding the Micro, Small and Medium Enterprises (MSMEs) sector of the economy is one key strategy to achieve economic growth and development. Micro, Small and Medium Enterprises (SMEs) scalability (growth or expansion) have become an area of concern for economic growth in developing economies(Asare, 2017).People use the term in reference to computer or other technological systems, but those in business also use the word to describe the adaptability of a company (Thibodeaux, 2015) in today's fast-paced business environment where the focus on customer satisfaction is at an all-time high (Mariwala, 2017). Scalability is essential in that it contributes to competitiveness, efficiency, reputation and quality. Small businesses must be particularly mindful of scalability because they have the biggest growth potential and need to maximize the return with resources (Thibodeaux, 2015). This article discusses the concept of scalability as it relates to business and non-scalable components of business process as well as the importance of being scalable. It also looked at some of the challenges and practices that prevent effective scalability of MSMEs in Nigeria and the way forward. As earlier stated, MSMEs are perceived as the key to Nigeria's economic growth, poverty alleviation and employment generation. But their unimpressive performance in employment generation and contribution to GDP in recent years has generated a lot of research interests.

2. Concept of Scalability

All young businesses are defined by an insatiable desire for growth. But there's a right way and wrong way when it comes to scaling up (Albanese, 2015). According to Campbellb (2017), Scalability is about capacity and capability. Does a business have the capacity to grow? Will a business systems, infrastructure and team be able to accommodate growth? Scaling a business means setting the stage to enable and support growth in your company. It means having the ability to grow without being hampered. It requires planning, some funding and the right systems, staff, processes, technology and partners (Campbell, 2017). Scalability, in the context of buying and selling in a business, refers to a company's ability to add significant revenue and not be constrained by its own structure and resources. When a company can quickly "scale up," it usually means it has the management, documented processes, information systems, and standard operating procedures to manage its own growth (divestopedia, n.d.).Scalability refers to the ability of a business to grow without losing customers, diminishing quality, or changing the core value proposition of the organization. In other words, it is developing products or services that people want and figuring out how to produce many of them for lower costs while selling more of them (Dudnik 2010). 
According to Mariwala (2017), scalability means growth which extends to your stakeholders; whether customers, employees or vendors. In other words, it is a positive influence that propels you further. Scalability describes how easy it is to expand a business model and grow its revenues significantly without equally increasing its cost base (Liu, n.d.).For a business, scalability means that you are prepared to handle an increasing number of customers, clients, and/or users (contegix, n.d.).

2. 1. Mathematical Illustration of Scalability

A good way to approach the meaning of scalability is through a slightly mathematical definition. This doesn't mean digging into derivatives or complex numbers, which we've all long since forgotten, but applying some basic mathematical ideas to the concept (Shawn, 2016);

The basic idea of scalability is this:

A product or service $\mathrm{X}$ is considered scalable, if: Delivering 20 of $\mathrm{X}$ is either...

- no more costly or difficult than, or

- only incrementally more costly or difficult than... delivering 10 of X.

And the corollary:

A product or service $\mathrm{X}$ is considered not scalable if: Delivering 20 of $\mathrm{X}$ is double or even more costly or difficult than delivering 10 of $\mathrm{X}$.

Or, it could be re-worded of this way:

If $\mathrm{Y}$ is the effort required to deliver $10 \mathrm{X}$, then:

- if delivering $20 \mathrm{X}$ requires $\sim 2 \mathrm{Y}$ or more, then $\mathrm{X}$ is not a scalable product or service.

- if delivering $20 \mathrm{X}$ requires $\mathrm{Y}$ or only a bit more than $\mathrm{Y}$, then $\mathrm{X}$ is a scalable product or service.

This is the heart of the idea of scalability. It's the difference between a linear and an exponential relationship between costs, revenue and product delivery. Naturally, these numbers are not hard and fast, and in reality business is generally much more complex, however the basic concept remains the same.

\section{Simple examples to illustrate}

Maybe some simple examples will make the concept clearer. These will be intentionally over-simplified to fit into a binary model;

\section{Example 1: Manually washing cars: not scalable}

Imagine that I wash cars for a living. Delivering the washing of a car involves a few basic variables (let's assume I already have the tools for the job):

- Selling the car wash to a person (convincing them that they should get their car washed by me) $==\mathrm{Y} 1==$ $\sim 10$ minutes

- Actually washing the car $==\mathrm{Y} 2==1$ hour

$\mathrm{Y} 1$ and Y2 are my "costs", together they are the Y from the definition above. Together they take about an hour of my time.

Now, it's easy to see that if I am manually washing cars one by one, then my business model is not scalable. Because, washing 20 cars is pretty much double the effort of washing 10 cars. Simple.

\section{Example 2: Teaching students: scalable}

Imagine I am a teacher of Chinese history. Delivering the education of Chinese history involves one basic variable; my time in the classroom (again, assuming I have the knowedge and expertise to teach) :

- It takes me 1 hour to deliver a lecture on Chinese history $==\mathrm{Y}$

However, let's imagine that in one class I have 10 students, and in the other class I have 20. By all accounts, in the classroom with 20 students, I am "delivering" more education, in theory, exactly double. But teaching 20 students was no more difficult than teaching 10 students. I delivered exactly the same lecture, however in the second case, twice the number of students attended. In this simple model, teaching Chinese history is a scalable exercise!

\section{Oversimplification}

These two examples are, of course, oversimplifications. But the essence of the idea of scalability is accurate. In example 1, the business model was less scalable than example 2 .

Naturally the real world involves many more variables. In the case of the car wash, I might have an advertisement sign outside that does my selling for me and so selling doesn't cost me any of my time. In the case of the teaching, the model breaks down as we keep adding students (we can only fit so many students into one of my lectures; the model scales only so much, then I have to break it out into two classes). But these variables can be plotted out and understood and ultimately fit into the model of scalability. 


\section{Real life scalability}

In the oversimplified examples above, scalability was treated like a binary property; either something is scalable or not. However, real life is, naturally, a lot more involved. Let's play with the concept a bit more by defining some limits to it and talking about additional variables:

\section{Upper limit: nothing is infinitely scalable}

Something would be infinitely scalable if the costs $\mathrm{Y}$, of delivering product $\mathrm{X}$, are not at all increased no matter how much of $\mathrm{X}$ we deliver. In the real world, this is simply not possible.

There are some products in reality that are highly scalable. One such area is something like a website. Imagine for instance this blog article. It's going to take me a certain amount of time to write it (our Y) - and if 10 people read it $(10 \mathrm{X})$ or 20 people read it $(20 \mathrm{X})$ the time it took me to write it is completely unaffected. Digital content is highly scalable. Imagine if 1000 people read this article - still, it only took me Y effort to produce it. What about 10000 ? 100000 ? Still, it only took me Y effort to produce it.

However, eventually my server can't handle the load. So I have to pay for a better server to host my content, and my $\mathrm{Y}$ has increased. Digital content is highly scalable, but not infinitely — nothing really is.

\section{Lower limit: increased efficiency as the genesis of scalability}

Let's return to the car example from above. Imagine I'm the guy out there washing the cars every day. Eventually I wake up and realize that I'm never going to scale my business very well. So I start thinking; how can I scale this up? Let's say I start to learn how to wash two cars in a little less than double the time it takes to wash one. For instance, I reclaim and re-use the water somehow, so I don't have to wait for the hosepipe for as much time. Or maybe I rinse and dry both cars at the same time side by side. Either way, I am finding ways to cut down the time usage.

Increased efficiency lies close to the genesis of scalability, but is not entirely the same thing. Increasing efficiency means reducing $\mathrm{Y}$ for the delivery of $10 \mathrm{X}$, which ultimately does mean delivering $20 \mathrm{X}$ takes less effort, however it is still $2 \mathrm{Y}$, even if $\mathrm{Y}$ itself is less.

\section{Scalable and non-scalable components of an overall business process}

In real life the process of delivering a product or service is not usually entirely scalable or non-scalable. Often, there are components or parts of the overall business process that are scalable to varying degrees (Shawn, 2016).

This example illustrates this idea quite nicely:

There are some guys in Dominoes pizza making some pizzas for customers. The creation of a pizza involves several steps. The chefs have to prepare the dough, put on the proper ingredients, and cook the pizza in the oven.

Interestingly, preparing the pizza is a non-scalable activity. A chef, no matter how good, can't prepare two pizzas for exactly the same effort as it takes to prepare one. Yes, perhaps he can work on ways to do it quicker, but he can't scale the preparation well.

However, two pizzas can be cooked in the oven at the same time. In fact, ten or even twenty pizzas can (assuming the oven to be quite big).

So, preparing the pizza is a non-scalable activity, but cooking the pizza is a more scalable activity.

So the delivery of the pizza to the customer involves both scalable and non-scalable parts of the process. Imagine further an even more nuanced scenario, also in our pizza story:

The pizza delivery driver is going to deliver two pizzas. Luckily, both customers are on the same street. So, delivering two pizzas took only a little more time than delivering one would have.

In fact, delivering 10 pizzas to the same street, assuming the distance from the pizza store to the street is way larger than the distance from the one house to the next on the same street, is almost the same effort as delivering 5 .

But, what if, in another scenario:

The pizza driver is going to deliver two pizzas. Unfortunately, both customer's houses are equidistant from the pizza store, and each other. Assuming the main cost of delivering a pizza is the time to drive to a location and the petrol associated with the driving, delivering two pizzas literally took double the effort than delivering one did.

And so we see that in the case of delivering pizzas, the scalability or non-scalability of an activity can depend on entirely random variables. Sure, we can look into optimising our pizza delivery routes, but ultimately that can only go so far.

2.2. The Importance of Being Scalable

As a business grows, its main objective is to continue to meet market demands. The trouble is, market demands are never static. They shift as people's interests and tastes change and as resources flow in and out of availability. If you want to stay competitive in these circumstances, you have to be able to change what you are doing to fill the needs and wants customers have in the moment.

Scalability also matters because growth in business means you are working with more customers, data and resources. If you do not have a way to handle these increases, you can lose efficiency, or the quality of your service or products can suffer. That can lead to poor customer relations and a lowered business reputation. 
From the financial perspective, scalability is critical because it lowers what you end up paying out. For example, if you have 100,000 clients and buy a technology system that can support a million customers, you don't have to replace that system (assuming it's still functioning well mechanically) when you reach 200,000 customers, 300,000 customers and so forth. In the same way, if you purchase state-of-the-art equipment, it won't become outdated as fast and you won't need to put money into new hardware for a while. If you're working in a scalable way, you end up getting more for your buck (touchsupport, n.d.).

\section{Literature Review}

The scalability of businesses is affected by the industries in which they operate. Some business models are easier to scale, while others can be much more challenging. As found by Sutton and Rao (2014), culture and structure are often more important than anything else. Businesses that produce a tangible product, such as the Clean Bottle case and the Greyston Bakery case, or most types of consumer purchased goods, are inherently simpler to scale. Small ventures of this type have many opportunities to achieve economies of scale, cost savings, and increased efficiencies. However, scaling up to achieve greater efficiencies and production levels exposes the entity to problems, such as decreased quality, lessened control over processes, and increased complexity. Another important aspect of scaling up for small businesses is customer value perception (CVP), where perceptions of organizations can change when they grow. The case of the Etsy Store Three Bird Nest illustrates CVP.

Kumar (2010) found that growing or scaling a business can be approached from two main perspectives regarding the timing of expansion. The question is a paradox: whether to grow in advance of demand with the hopes of capturing maximum market share and minimizing foregone revenue; or, more conservatively, does the business grow when demand already exists? Increasing the scale of a business in advance of real demand relies on careful forecasting and represents a greater risk. However, waiting to grow could result in the business losing customers to competitors and potentially missing an entire swing in the market. While many factors go into the decision to grow a business, forecasts are ultimately only accurate to a certain extent, and as new ventures are formed they must decide how they will approach such an important part of the life of their business. Consequently, the environment of forecasting and planning has changed because forecast-based planning methods and/or budget-oriented planning are alone not sufficient for any business to be sustainable.

Clean Bottle (2015) offers a line of water bottles that come apart at both the top and bottom for thorough cleaning and ease of maintenance. Clean Bottle was born of the increasingly popular "crowd funding." Crowd funding is a model of bringing new products to market with individuals pledging money, but their funds are only used if enough pledges are made to reach a specific threshold. Clean Bottle set the goal for their crowd funding campaign at $\$ 20,000$, and nearly doubled it before their deadline. Clean Bottle is a successful example of scalability because it offers a product that requires little inputs beyond basic manufacturing.

\section{Micro, Small and Medium Enterprises and Scalability}

All businesses need to be scalable on one or more levels in order to hold onto and build market share. Even so, MSMEs have the greatest need for scalability because they are the ones with the biggest potential for growth. They are the organizations that have to be more careful with the limited resources they have, the ones that go through metamorphoses as their leaders become more familiar with the business game. Many MSMEs fold directly because they fail to foresee what they might need or where the market can take them, having too much of a here-and-now mindset.

It is natural for MSMEs to want to make as many areas scalable as possible and business leaders should work toward this goal. Still, you should recognize that not everything might be scalable. A lack of scalability in one or more areas doesn't necessarily stop you from moving forward. For this reason, it's just as important to recognize where you can't change as to see where you can (touchsupport, n.d.).

4.1. Challenges and Practices that Prevent Effective Scalability of MSMEs in Nigeria

MSMEs in Nigeria achieve a much more relative high value added operations because they are propelled by basic economic activities that depend mostly on locally sourced raw materials; they provide feeder industry services as they serve as major suppliers of intermediate goods and components to large-scale industries as well as major agents for the distribution of final products of such industries; they provide opportunities for the development of local skills and technology acquisition through adaptation, etc. Despite the catalytic role of MSMEs in Nigeria, the development of its viability has over the years been challenged by a number of harsh economic conditions which characterize the Nigerian business environment. Some of these challenges have been outlined by the Institute of Development Administrator of Nigeria (IDAN, 2007).Here is a look at how these challenges affect the scalability of MSMEs in Nigeria.

\section{Financial Problems}

It is natural for business owners to want to expand operations and put their business on a growth path; however, this move requires not only a winning strategy based on market realities, but also the appropriate source of finance. This 
could scale up or breakdown a business. Using the correct mix of financial options is very important for scalability of business. There is no question that expansion requires money, and rather than use up business's working capital, choose the right finance from the market. Today micro, small and medium enterprises have access to numerous sources of finance, each with its own unique features and benefits. It is important for business owners to carefully identify the attributes of each option and choose the ones that work best. Instead of going for funding from one source, mix it up. Take a business loan, accept equity investors and see if the suppliers will give credit. Doing this spreads the risk and is faster than just waiting for a venture capital investment, which will also dilute one's ownership (The HANS India, 2017).

Ekpenyong (1997) and Utomi (1997) identified inadequate capital, inaccessible credit facilities as some of the problems bedeviling the MSMEs in Nigeria. Long term development institutional credit is known not to be available to MSMEs because they are generally considered high credit risks by financial institutions. The study by Evbuomwan, et al. (2012) indicated that $75.7 \%$ of their survey respondents relied mostly on own funds to finance their businesses.

However, the MSMEs lack of access to relative cheap and effective sources of finance has been identified as the major factor hindering their contribution to economic growth. A widespread concern is that the banking system in the sub-sector (which supposed to be the major financier of MSMEs) is not providing enough support to new economic initiatives and in particular to the expansion of MSMEs.

\section{Management Problems}

Growth and scalability of business requires an expanded skill set. As such, entrepreneurs are advised to build a team with broad and complementary skills. Unfortunately, the lack of trained manpower and management skills also constitute a major challenge to the survival and scalability of MSMEs in Nigeria. According to West and Wood (1972), “...90\% of all these business failures result from lack of experience and competence."

\section{Poor Documentation of Business Process}

MSMEs in Nigeria are usually characterized by poor record keeping. As their business grows, so is the business processes, but they do not document the process let alone update the documentation. Many owners of MSMEs in the country do not build their business so that when they die someone could come in, read their business process manual, and know exactly how the business operates. A documented process is good for scaling of MSMEs, it is also good for selling a business.

\section{Marketing}

Growing and scaling up a business always leads back to marketing and sales. Even if a business firm has an inspirational vision, has a solid team behind that vision, and have an awesome process, it is nothing without revenue. If it has to scale, it will need to learn how to market it product or service and create sales. However, most Nigerian MSMEs owners equate 'marketing' to 'selling' and this is reflected in their various dysfunctional business behavior against customer satisfaction and good business and marking orientation. They lack the knowledge and skills of basic marketing ingredients - marketing research, market segmentation, and marketing planning and control. The outcome of this is poor quality products, unawareness of competition, poor promotion, poor distribution, and poor pricing methods (Ayozie, 2013).

\section{Inadequate Basic Infrastructure}

Government has not done enough to create the best conducive environment for the striving of SMEs, the problem of infrastructures ranges from shortage of water supply, inadequate transport systems, lack of electricity to improper solid waste management. Nigeria's underdeveloped physical and social infrastructures create a binding constraint to SMEs growth, since; they heavily rely on the inefficiently provided state infrastructures and cannot afford the cost of developing alternatives. This increases cost and reduces efficiency as well as scalability.

\section{Cash flow problems}

A cash flow problem arises when a business struggles to pay its debts as they become due. Note that a cash flow problem is not necessarily the same as experiencing a cash outflow. A business often experiences a net cash outflow, for example when making a large payment for raw materials, new equipment or where there is a seasonal drop in demand. However, when cash flow is consistently negative and the business uses up its cash balances, then the problem becomes serious (Tutor $2 u, n . d$.$) . The main causes of cash flow problems are: low profits or (worse) losses,$ over-investment in capacity, too much stock, high overhead expenses, and allowing customers too much credit. Also, fast growth can cause real cash flow problems when the large number of new customers takes time to pay while the growing business expenses need to be paid right away.

Just as good cash flow keeps a business afloat, poor cash flow can sink it (FreshBooks, n.d.). In fact, poor cash flow is a big reason why one in every four businesses doesn't make it past the first year. And why more than half don't survive past the fifth. It is extremely difficult to scale a business if cash flow management processes are lacking. Unfortunately, many MSMEs in Nigeria do not know how to create a good cash flow stream. Most of the MSMEs 
encounter a cash flow problem at one time or another. Fortunately, most cash flow problems can be prevented with a bit of preparation and the right strategy.

\section{Investment Culture Problems}

Investment is the purchase of an asset with the hope that it will generate income or appreciate in the future. It involves committing money into an investment vehicle in the hope of making a financial gain with the possibility of losing it. Most Nigerian Entrepreneurs do not have the investment culture of ploughing back profits. Bala (2002) stressed that the attitude of a typical Nigerian entrepreneur is to invest today and reap tomorrow. Also, the sociopolitical ambitions of some entrepreneurs may lead to the diversion of valuable funds and energy from business to social waste.

\section{Labor Intensive}

It is emphasized that the small scale enterprises make the possibility of the equitable distribution of national income more realistic of providing employment opportunities on a large scale. By creating more employment it help mobilizing capital and human resources that would otherwise be left idle.

The 2012 Enterprise Baseline Survey revealed that there are 17 million Small and Medium Scale Enterprises in Nigeria, employing 32.41 million persons and makes a contribution of about 46.54 per cent to the nation's Gross Domestic Product in nominal terms (Elebeke, 2012). However, MSMEs that is labor intensive and staff intensive is not scalable. MSMEs have start looking at production automation, proven process technologies, and minimum staff approaches, to begin scaling.

\section{ICT Issue}

Currently across the globe, there has been a paradigm shift in the mode of operations of MSMEs, to move from a matter based economy to a knowledge based economy. In recent years, it's been seen that one of the major drivers of MSMEs growth in developed countries has been attributed to the increasing use of Information and Communication Technology (ICT). ICT utilization is very important in the 21st century as they make ease business transactions, improve customer and consumer relationship and also panacea to combat a number of challenges facing MSMEs. Ashrafi and Murtaza (2008) state that organizations around the globe are utilizing ICT to cut cost, improve efficiency and offer greater customer service, despite the high diffusion of digital technologies from developed economies to developing economies in recent years, the use of ICT within MSMEs in Nigeria remains low (Apulu and Latham, 2009). This probably is due to employee's ICT illiteracy or employer's ICT illiteracy, cost of ICT equipment, entrepreneurs not seeing the competitive pressure in the market strong enough for them to adopting ICT, etc.

4.2. Towards making Micro, Small and Medium Scale Enterprises Scalable in Nigeria

Growth without a large increase in cost is tricky. Studying and crafting a scalable business model can help in both the short term and long term with the end result being both growth and profitability. The overall goal is to increase revenue without a cost growth. Here are some factors for MSMEs in Nigeria to consider in scaling up their businesses:

\section{a) Evaluating and Planning}

A firm has to take a hard look inside its business to see if it is ready for growth. This means taking stock of where a firm's business stands today. It has to strategize what needs to be done to increase sales. Then assuming a firm's orders doubled or tripled overnight. Does the organization have the people and systems to handle those new orders, without failing? This is where a good plan is essential. One of the best planning starts with a detailed sales growth forecast, broken down by number of new customers, orders and revenue that a firm intends to generated. A spreadsheet should be included that breaks the numbers down by month. The more specific a firm is, the more realistic it sales acquisition plan can be. Then a similar expense forecast should be done based on adding technology, people, infrastructure and systems to handle all those new sales orders. Some hard thinking and research needs to be done to come up with proper cost estimates, however, doing so will make the plan better (Campbell, 2017).

\section{b) Timing}

The timing of MSMEs' product or service must be right in the marketplace. MSMEs need to anticipate their market and customers' needs and constantly innovate to stay ahead. This requires leadership with agility, resilience, and a willingness to fail-and to recognize that failure quickly enough to adapt and move forward.

\section{c) Branding}

Today's economy requires business leaders to create positive memories for customers and partners, or customers will turn to a competitor in search of a better experience. For MSMEs to create a scalable business, they have to understand just how crucial it is to build brand equity. The emotional attachment that links customers to their product, as opposed to any other, translates into sustainable growth (FASTCOMPANY, 2013). To achieve this, it will require choosing a target audience; connecting with the public to make them feel an emotional attachment to a firm's brand; inspiring and influence the audience through brand message; and reinforceing the brand image within 
the MSMEs (i.e., making sure employees at every level of the organization work and behave in a way that reinforces firm's brand image).

\section{d) Sales Scale Up}

Creating a unique product and a unique brand is not enough. MSMEs will need to develop repeatable sales processes to create a scalable business. It is one thing to sign up a few customers; it is another thing entirely to identify, design, and implement repeatable sales and customer delivery processes (FASTCOMPANY, 2013). To ensure that a repeatable and scalable sales model is created, MSMEs need to: increase the sources of their customer leads on a consistent basis; sales conversion rate and revenue must be consistently forecasted; the cost to acquire a new customer must be significantly less than the amount that can be earned from that customer over time; and customers should get the right product in the right place at the right time.

\section{e) Finding and Establishing Key Relationships and Networks}

MSMEs can catalyze their businesses' growth by building and fostering critical relationships. Even if they are good in their area of core competency and have deep domain expertise at what they do and the value they bring to their customers. But in the end, it comes down to connections (Wagner, 2013).

\section{f) Evaluate Financing Options for Expansion}

There are very few big businesses that are self-funded, however, whether a firm wants to expand its employee base, buy a new facility or develop a new product, one of the key elements in taking a firm to the next level is knowing the kind of capital it needs to support that growth, hence, MSMEs must evaluate the financing options available for them to expand (Wagner, 2013).

\section{g) Technology Embracement}

MSMEs need to take better advantage of technology innovations to help manage their business. If a small business can identify a genuine need, technology likely exists to fulfill that need both locally and globally. The last two decades have marked an enormous increase in technology use in business. Through advancement in technology in computers and the internet, small businesses are contributing more to the economy than in the past. Technology has made it easy in processing daily business activities and routine tasks. Technology has tangible and intangible benefits in a small business that affect the culture, relationships and efficiency of an enterprise (Advance Funds Network, n.d.).

\section{h) Automate solutions}

MSMEs should appraise their business processes. There are always repeated steps and circular activities that can be automated. This frees time for focusing on business growth. Staff work-hours should be minimized. For example, instead of depending on manual data entry and appointments setting, invest in a system that simplifies work process for employees. Newcomers can then be trained quickly and easily and join the workflow without delay (Mightycall Team, 2016). In sum automation can help run a business at lower cost and more efficiently by minimizing manual work

\section{i) Establish standardized processes}

If a start-up is going to scale, managers need to implement standardized and repeatable processes, with proper delegation. This may require investments in purchasing support systems including IT and training personnel accordingly, as well as delegation from the founder and senior management (Salter, 2016).

\section{j) Reduction of Risks}

Risk is an inevitable part of starting and growing a business. It's impossible to control everything, but there are plenty of ways to limit internal and external threats to a firm and its growth. One important resource to help you accomplish this is a business insurance provider. Small businesses should be prepared by seeking insurance products that help them recover from any loss, including those that cover the cost of remediation and lawsuits. According to Gausepohl (2016), as small businesses grow, they may add space or equipment, create new products or services, or increase their operating and distribution footprint, it is wise for periodically reviewing of their insurance policy to ensure they have the right coverage.

\section{k) Team Building}

The biggest challenge in scaling any business is people. The faster the growth, the harder it is to add enough skilled people to keep from tipping over. If a firm accelerates its growth but does not have a team that supports its customers and maintains a high level of service, development and refinement, it will eventually collapse in on itself. There are two parts to this: First is hiring. It is important to spend time to put the right people in place. The second is creating a fertile work environment for growth (Gerber, 2016).

\section{l) Marketing}

Firms should not delay an efficient marketing strategy if it wants small business to become a market leader. The startup needs to be noticed at once. It's not about local promos and advertising campaigns, which are useful to attract clients here and now. It is about joining a global market(Mightycall Team, 2016). It important to get access 
to business conferences, participate in workshops. These are places to make business networking and make proper acquaintances in different fields. Social media is a rich platform of information, communities and events agenda. Marketing is a continual process. MSMEs need to keep updating their product line, so they can attract new clients.

5. Conclusion

All businesses need to be scalable on one or more levels in order to hold onto and build market share. Even so, Micro, Small and Medium Enterprises have the greatest need for scalability because they are the ones with the biggest potential for growth. They are the organizations that have to be more careful with the limited resources they have, the ones that go through metamorphoses as their leaders become more familiar with the business game. Many MSMEs fold directly because they fail to foresee what they might need or where the market can take them, having too much of a here-and-now mindset. Although many areas in a business are scalable, some are not. It's just as important to recognize where cannot be changed as to see where can be changed.

References

Albanese, J.(2015). How to Scale a Business: 4 Growth Tips from Actual Experience. https://www.inc.com/jasonalbanese/how-to-scale-a-business-4-growth-tips-from-actual-experience.html

ADB (2002).Technical Assistance for the Development of a Framework for SME Support. Asian Development Bank.

Asare, J. (2017).Approach to Assess and Select Small and Medium Enterprises (SMEs) for Incubation on the Base of Angel Model - a Case on Developing Economies and ENGINE Program. British Journal of Economics, Management \& Trade, 17(3), 1-28,

Ashrafi, R., and Murtaza, M. (2008).Use and Impact of ICT on SMEs in Oman.The Electronic Journal Information Systems (Vol. 11).

Apulu, I., and Ige, O. (2011). Are Nigeria SMEs Effectively Utilizing ICT? International Journal of Business and Management, Vol.6. No 6.

Ayozie, D. O., Oboreh, J. S.,Umokoro, F., and Ayozie, V. C. (2013). Small and Medium Scale Enterprises (SMEs) in Nigeria: The Marketing Interface. Global Journal of Management and Business Research.13(9). Available at: https://globaljournals.org/GJMBR_Volume13/1-Small-and-Medium-Scale-Enterprises.pdf.

Advance Funds Network (n.d.). Importance of Technology for Small Business in Growing the Economy.https://www.advancefundsnetwork.com/importance-of-technology-for-small-business-ingrowing-the-economy/

Bala, J.J. (2002). The Nigerian Investment Promotion Commission and prospects for investment by Small Scale Enterprises with the new democratic dispensation presented at the seminar on the Strategies and Policies for the support of Small Scale Industries in Nigeria held at Abuja in May.

Campbell, A. (2017). How to Scale a Business. https://www.score.org/blog/how-scale-business

Clean Bottle (2015). Clean Bottle - Guaranteed For Life. http://www.cleanbottle.com. Retrieved from the web on 13 March 2015.

Contegix (n.d.).Why Is Scalability Important for My Business?https://www.contegix.com/why-is-scalabilityimportant-for-my-business/.

Dudnik, N. (2010). "Social Entrepreneurs' Tricky Issues of Sustainability and Scale." Harvard Business Review. Divestopedia(n.d.).Scalability.https://www.divestopedia.com/definition/970/scalability

Ekpenyong, D. B. (1997). "Problems of Small Business and why they Fail." Journal of General Studies, Bayero, University, Vol. 3, No.1

Elebeke,E. (2012).SMEs contribute half of Nigeria's GDP. https://www.vanguardngr.com/2012/12/smes-contributehalf-of-nigerias-gdp/

Etuk, R. U., Etuk, G. R., and Michael, B. (2014).Small And Medium Scale Enterprises (SMEs) And Nigeria's Economic Development.Mediterranean Journal of Social Sciences, 5(7), 656- 662.

Evbuomwan, G. O., Ikpi, A. E., Okoruwa, V. O., and Akinyosoye, V. O. (2012)."Preferences of Micro, Small and Medium Scale Enterprises to Financial Products in Nigeria".Journal of Agricultural Economics and Development, 1(4), 80-98.

FASTCOMPANY (2013). 5 Essential Principles For Growing Your Small Business. https://www.fastcompany.com/3004395/5-essential-principles-growing-your-small-business

FreshBooks (n.d.).How to Solve 6 Common Cash Flow Problems in Your Business. https://www.freshbooks.com/blog/6-ways-to-avoid-cash-flow-problems-in-your-business 
Gausepohl, S. (2016). 7 Secrets for Growing Your Business Quickly. https://www.businessnewsdaily.com/7690rapid-business-growth-tips.html

Gerber, M. E. (2016). How To Grow Your Business Fast: 50+ Experts Share Their Best Scaling \& Growth Hacks. http://beyondemyth.com/blog/grow-your-business/

IFC (2006). "Micro, Small and Medium Enterprise: A Collection of Published Data", in Newberry, Derek (2006). The Role of Small- and Medium-sized Enterprise in the Future of Emerging Economies. Earth Trends 2006. World Resources Institute under a CreativeCommon License.

Kumar, D. (2010). Enterprise Growth Strategy: Vision Planning and Execution. Ashgate Publishing Group.

Liu, I. (n.d.).Examples of a Scalable Business Model.http://smallbusiness.chron.com/examples-scalable-businessmodel-25576.html

Mariwala, H. (2017). The Importance of Scalability.https://inc42.com/entrepreneurship/the-importance-ofscalability/

Mightycall Team (2016). 7 Tips to Make Your Business Scalable.https://www.mightycall.com/blog/7-tips-makebusiness-scalable/

Salter, P. (2016). The Six Steps To Scaling A Business.https://www.forbes.com/sites/philipsalter/2016/05/02/thesix-steps-to-scaling-a-business/\#650a99801ca9

Shawn, P. (2016). What is Scalability in Business?http://shawnpowrie.com/business/scalability/

Sutton, R., Rao, H. (2014). Scaling Up Excellence: Getting to More without Settling for Less. Crown Publishing Group.

The HANS India (2017).How to Finance The Scale-up of Your Company. http://www.thehansindia.com/posts/index/Business/2017-08-04/How-to-Finance-The-Scale-up-of-YourCompany/316747

Thibodeaux, W.M. (2015).What Is Scalability, and Why Does It Matter to Your Business?https://www.touchsupport.com/what-is-scalability-and-why-does-it-matter-to-your-business/

Touchsupport (n.d.).What Is Scalability, and Why Does It Matter to Your Business?https://www.touchsupport.com/what-is-scalability-and-why-does-it-matter-to-your-business/

Tutor2u (n.d.).Finance: Causes of Cash Flow Problems(GCSE).https://www.tutor2u.net/business/reference/financecauses-of-cash-flow-problems

UNCTAD (2001). Reports on the Expert Meetings on Improving Competitiveness of SMEs in Developing Countries: The Role of Finance, including E-finance, to Enhance Enterprise Development. United Nation Council on Trade and Development.

Utomi, P. (1997). "The Role of Higher Institutions in Promoting Entrepreneurship and Small Businesses in a Developing Economy: Lesson From Experience." In FadahunsiGlu and Tunji, Daoduedts., Small and Medium Enterprises Development: Policies, Programmes and Prospects. West African Management Development Institutes Network (W AMDEVN): pp. 120 - 128.

West; D., and Wood, G. (1972). Financial Management. U.S.A. Hayuton Muffin Company.

Wagner ,E. T. (2013). 5 Steps to Scale Your Business (You Won't Make it Otherwise).https://www.forbes.com/sites/ericwagner/2013/11/20/5-steps-to-scale-your-business-you-wontmake-it-otherwise/\#401d49b512cf

\section{Copyrights}

Copyright for this article is retained by the author(s), with first publication rights granted to the journal.

This is an open-access article distributed under the terms and conditions of the Creative Commons Attribution license (http://creativecommons.org/licenses/by/4.0/). 